\title{
Antropoplástico: Desdobramentos em arte a partir do desenho paramétrico e da fabricação digital
}

\author{
Antropoplástico: Developments in art from the parametric design and digital fabrication
}

\author{
Thiago Matheus Costa Guedes \\ Universidade Federal de Pelotas, Brasil \\ cstguedes@gmail.com \\ Daniel Albernaz Acosta \\ Universidade Federal de Pelotas, Brasil \\ d.acosta@terra.com.br
}

Adriane Borda

Universidade Federal de Pelotas, Brasil

adribord@hotmail.com

\author{
Cristiano Correa Ferreira \\ Universidade Federal do Pampa \\ cristiano.ferreira@unipampa.edu.br \\ Gabriela Gonzalez Peronti \\ Universidade Federal de Pelotas, Brasil \\ ga.peronti@gmail.com \\ Valentina Toaldo Brum \\ Universidade Federal de Pelotas, Brasil \\ valentinatbrum@hotmail.com
}

\begin{abstract}
The present article represents a series of contextual works started through the collection of a stone. The process occurred during an artistic residency in Argentine Patagonia. This procedural event shows interest in investigating situations of geometrization and scale between body, object and landscape. Resulting of these works from the residency experience I present a research which focuses on an artistic view between the fields of art and architecture.
\end{abstract}

Keywords: Geometrization of landscape; body scale; resonant place; art-architecture

\section{Introdução}

Reside em uma pedra coletada durante derivas pelo deserto na Patagônia Argentina a intenção em construir um espaço a partir da escala de um corpo determinado (do artista, primeiro autor deste trabalho). Um lugar ressonante híbrido que transite entre ser um abrigo, observatório, objeto transitório na paisagem, ou menir. Para construir esse espaço que emerge em direção a uma "quase arquitetura" foi necessário entender o trabalho dentro de uma trajetória processual, que se desenvolve em diferentes direções, linguagens $e$ procedimentos entre os territórios da arte e da representação gráfica digital.

É objeto central dessa pesquisa poética investigar situações limítrofes que transformam uma paisagem natural em artificial, além das relações de escala entre a paisagem, o corpo e o objeto de arte sob tais circunstâncias. Pensando que a presença do corpo em si pode ser uma maneira de artificializar e domesticar uma paisagem, Antropoplástico é a transposição entre um fragmento síntese primitivo da paisagem (pedra), traduzida para uma representação sintética mediada pela escala do corpo.

Em um primeiro instante o processo remete ao movimento artístico da Land Art. Onde a percepção dos objetos minimalistas fez com que se evidenciasse o espaço que 0 circunda. Essa percepção fez com que o artista fosse em direção à paisagem para se apropriar dos elementos circunstanciais que nela se encontram, modificá-los, e com isso atribuir um novo significado ao lugar.
A etapa seguinte a esta experiência direta com a paisagem se desenvolve no campo da modelagem gráfica digital. $O$ modelo (pedra) foi escaneado e seus parâmetros alterados no espaço virtual a partir da escala específica do corpo do artista. Entendendo estecomo parâmetro de transformação das coisas que estão a sua volta, permitiu compreender seu corpo como uma ferramenta tecnológica contextual, e a interface do software como uma paisagem virtual de tradução dos parâmetros.

O movimento de tradução que se estabelece entre o espaço virtual e o espaço real, segundo Walter Benjamin, permite com que haja uma sobrevida do original e ao mesmo tempo sua falência. Constitui-se como objetivo investigar o quanto e o que se conserva das propriedades do modelo original diante do processo trans-formato de um objeto para um meio de expressão. Nicolas Bourriaud afirma que a topologia e a tradução são práticas de deslocamento e questiona: "o que é que se mantém em um objeto e o que é que se perde na operação que consiste em reconfigurar suas propriedades e coordenadas?". (BOURRIAUD, 2011, p.138).

A revisão teórica dessa pesquisa constitui em averiguar uma bibliografia multidisciplinar que contemple e estabeleça tangências entre as áreas de interesse circunscritas aqui. Entendemos que para contribuir com o assunto proposto nesse artigo é preciso tencionar os campos de atuação para encontrar na intersecção das esferas de conhecimento um lugar comum entre linguagens. Com base nisso foi proposto um olhar do ponto de vista da arte contemporânea projetado 
para os circuitos da representação e fabricação digitalBreve Relato

A experiência aqui relatada teve início em uma residência artística no deserto da região central da Patagônia Argentina. Esse lugar abrigou temporariamente uma série de acontecimentos e proposições artísticas que surgiram das características circunstanciais do próprio lugar. A proposta de habitar por um mês essa espacialidade consistiu em criar um deslocamento geográfico radical, onde os artistas puderam vivenciar uma certa condição de isolamento.

Por esse motivo, todo acesso a algum tipo de tecnologia de fabricação era escasso. Os trabalhos surgiam de elementos do lugar para evidenciar questões relativas ao próprio lugar. Essa condição de suficiência motivou a identificação no terreno de aspectos que o tornam inóspito e adverso para o habitar. Porém, surgiu em paralelo a essa questão a ideia de um habitat nômade, que se deslocasse pelo território.

Habitar um lugar pode ser uma maneira de artificializa-lo, pois altera as condições com que os elementos desse lugar se transformam ao acaso. Em um terreno de condições adversas a primeira providência é abrigar-se, e para isso é preciso construir.

Os antigos povos nômades inventaram uma forma particular de ressignificar a paisagem com um objetivo prático, que era orientar o deslocamento dos viajantes até seu destino: "É provável que também tenha sido para estabilizar a direção vertical que se criou o primeiro elemento artificial do espaço: o menir" (Careri, 2013, p. 52). Essas pedras alongadas fincadas no solo datam pela primeira vez do período neolítico, e representam a primeira transformação física da paisagem ${ }^{1}$

Mais adiante, os artistas do pós-minimalismo deixaram o espaço fechado dos museus e se projetaram em direção à paisagem aberta para criar suas obras. Nos campos e periferias dos centros urbanos, artistas, como Robert Smithson, Richard Long e Carl André, pensavam seus trabalhos em um determinado lugar específico da paisagem onde eram executados. Obras como as desses artistas levantaram uma questão crucial para a compreensão espacial do trabalho, pois está implícita a condição da percepção dessa obra em relação ao contexto e não mais à neutralidade do "cubo branco", lugar institucionalizado da arte. Por sua vez, essa percepção acontece concomitante à experiência do espaço físico pelo observador, sobre essa triangulação observador - obra - espaço, Robert Morris denomina duração o tempo presente da "experiência espacial imediata". Diz este autor que um determinado observador ocupa um lugar específico diante da obra. No caso da escultura o observador circunda o objeto. Já em um objeto de dimensões arquitetônicas, ou a própria arquitetura, o mesmo observador é circundado pelo trabalho. Essa outra percepção faz com que o mesmo observador leve em consideração o contexto onde a obra surgiu e onde está instalada, os materiais empregados e como se chegou a sua forma. No segundo caso, o lugar nunca é neutro, ao contrário, é um potencializador.

\section{Antropoplástico}

Passada essa experiência de imersão na residência artística, materiais de registro e fragmentos de trabalhos que haviam ficado transitoriamente na paisagem foram trazidos para 0 laboratório. Passou-se então a realizar operações projetuais interligadas com a investigação prática sobre softwares utilizados em projetos arquitetônicos para se refletir sobre diferentes maneiras de obtenção de imagens. Com uma dessas imagens, projetou-se uma série de manuais que consistem em uma proposição para a ampliação em escala global da imagem em negativo de uma pedra específica coletada. Os manuais também sugerem um deslocamento que interligaria pontos em lugares remotos do planeta através de coordenadas geográficas. Talvez a potência desse trabalho resida na liberdade de projeção de sua impossibilidade.

De acordo com o manual, em cada ponto do mapa seria inserida uma reprodução da pedra impressa em material plástico. A imagem em negativo seria formada por linhas imaginárias interligadas, que se comportariam como trópicos, delimitando territórios e criando uma espécie de arqueologia poética do plástico. Os manuais foram criados para serem impressos ou disponibilizados para download na internet em formato PDF².

Figura 1: Imagem em negativo da pedra em escala ampliada, 2015

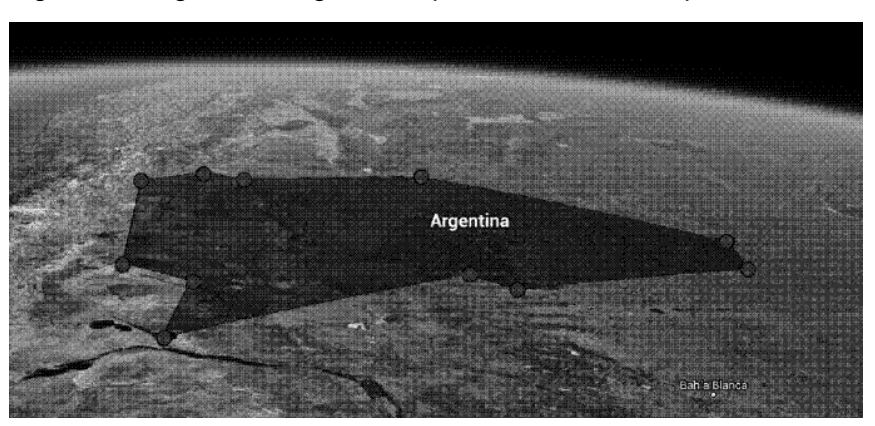

A princípio, para reproduzir exemplares impressos da pedra que seriam utilizados como prevê o manual, o modelo original foi enviado para o Núcleo de Desenho Técnico em Arquitetura da Universidade Federal do Pampa na cidade rio-grandense de Bagé, por onde o modelo foi submetido a um aparelho de scanner $3 D$. A representação que surge simultaneamente como resultado de um processo de transferência do ambiente real para o virtual, inaugura a possibilidade de sua deformação no campo virtual. A representação do modelo (nuvem de pontos) foi processada para ser transformada novamente em

1 "A palavra menir deriva do dialeto bretão e significa literalmente "pedra longa". O erguimento do menir representa a primeira transformação física da paisagem de um estado natural a um estado artificial. O menir é a nova presença no espaço do neolítico, é o objeto ao mesmo tempo abstrato e vivente a partir do qual, a seguir, se desenvolveram a arquitetura (a coluna tripartida) e a escultura (a lápide-estátua) "

\footnotetext{
2 site: http: //thiagocostaguedes.tumblr.com/
} 
uma superfície poliédrica configurada por uma densa malha triangular que conecta cada um dos pontos.

Alguns desses pontos de vista foram selecionados durante 0 escaneamento do modelo de acordo com sua topografia. As seções obtidas foram ampliadas, os relevos da superfície da pedra formam um mapa topográfico, remetem ao formato de curvas tomográficas, as quais remetem ao lugar onde o modelo (pedra) foi encontrado. Essas seções foram gravadas e cortadas a laser em acrílico. O múltiplo é composto por sete peças fixadas por uma dobradiça universal e mantidas a uma distância de cinco centímetros da parede. Cada peça é direcionada para um lado aleatório de tal forma que o conjunto insinue uma turbulência (figura 2).

Figura 2: Objeto topográfico da pedra, 2015

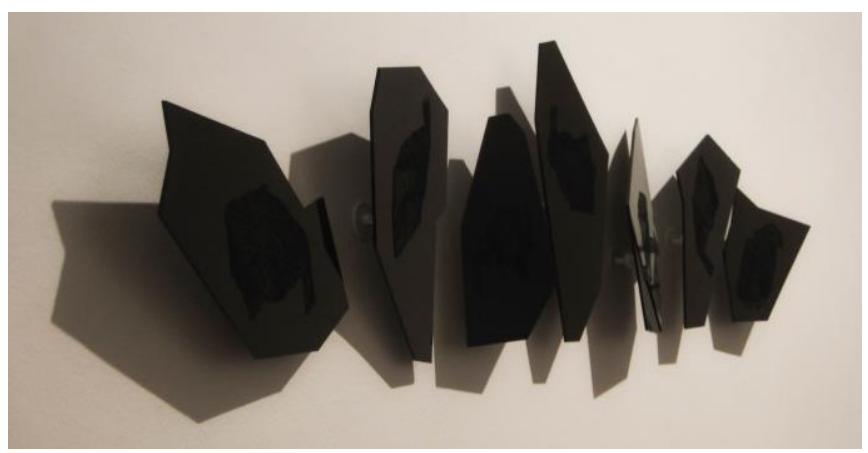

\section{Antropometria}

A partir do processo de digitalização tridimensional (scanner 3D Creaform, categoria Handyscan, modelo Uniscan, tempo de leitura de 18.000 medidas $/ \mathrm{s}$, resolução de $0.100 \mathrm{~mm}$, precisão de até $0.08 \mathrm{~mm}$ ). Configurou-se uma nuvem de pontos e, a partir dela uma densa malha triangular que conecta cada um dos pontos para gerar a superfície poligonal que quer representar a forma. Essa é a execução do primeiro momento do processo trans-formato: a falência do original e a formação de uma imagem virtual.

A lógica antropométrica utilizada para controlar a densidade da malha transformando o modelo foi a altura do corpo do artista $(1,75 \mathrm{~m})$, que é uma estratégia recorrente no seu processo criativo, esta malha foi sendo simplificada. Foram empregadas as técnicas de desenho paramétrico para associar o referido parâmetro de altura como fator para a redução do número de polígonos da malha.

Este processo, realizado por meio das ferramentas de modelagem digital (Rhinoceros/Grasshopper) deu origem a quinze exemplares diferentes do modelo. Desta maneira, estas representações foram se deformando e perdendo gradativamente o número de polígonos numa tendência ao tetraedro, poliedro com o menor número de faces, distanciando-se das características que o definiam, como textura, peso e forma. Cada novo exemplar é uma possibilidade que se expande, como um gradiente tridimensional da materialidade do modelo, com um controle relativo sobre como essa deformação irá acontecer, torna imprevisível o resultado desse processo.

Figura 3: Exemplares da pedra, processo antropométrico, 2015.

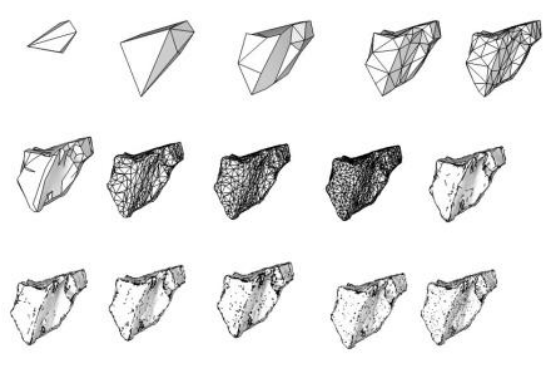

O passo seguinte foi imprimir em material plástico (PLA) exemplares tridimensionais da pedra por uma impressora 3D que se utiliza de um processo de fusão e depósito por camadas - FDM. Para garantir a reprodução das características irregulares de toda a superfície do modelo, por este método de impressão, foi conveniente seccioná-lo em duas partes. As bases de cada uma das partes correspondem à seção do modelo, tendo sido coladas de maneira a tentar reproduzir o mais fiel possível à geometria da pedra com toda sua superfície rugosa.

Quanto ao resultado (figura 2), não podemos dizer que o exemplar impresso, à direita da figura, é exatamente uma cópia. Talvez o correto seja afirmar que se originou um novo objeto, pertencente de características próprias e imanentes. Nesse caso o conceito de desenho paramétrico foi usado para transformar um modelo existente.

figura 4: Pedra (esq.), exemplar impresso (dir.), 2015

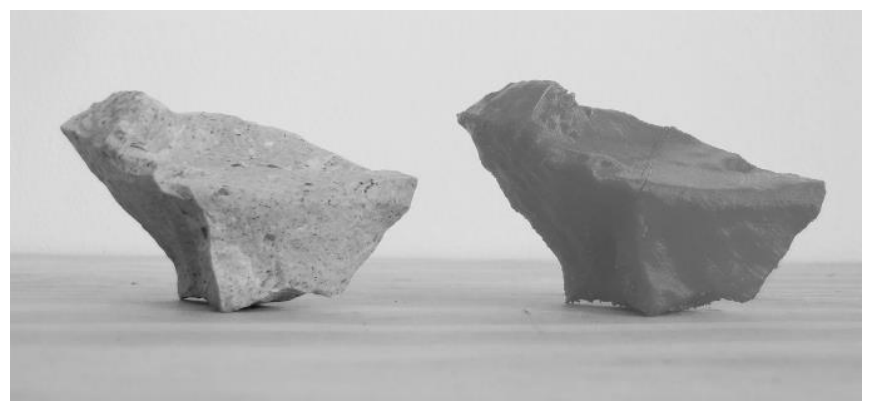

\section{$\mathbf{P 1}+\mathbf{P} 2$}

Com base nos procedimentos anteriores adotados a partir do uso da escala do corpo como parâmetro de deformação do modelo, esse projeto prevê a construção de um protótipo espacialidade nômade - chamado aqui provisoriamente de P1 e P2 (figura 3), e se insere no âmbito dessa pesquisa como um dos desdobramentos do processo de antropometria e modelagem paramétrica. Os protótipos são constituídos por dois elementos complementares que correspondem aos dois últimos exemplares impressos da pedra, respectivamente os que perderam o maior número de polígonos durante 0 processo antropométrico conforme a figura 1.

Nesse ponto, a pesquisa toma uma corrente em direção à definição das características espaciais desses protótipos, levando em consideração que não existe necessariamente uma função específica para o uso, mas que pode assumir uma função ambígua e transitar entre abrigo - observatório - objeto. 
É certo dizer que sua forma é oriunda das condições de campo, da especificidade do lugar e da articulação do meio. Em oposição a uma modificação da paisagem imposta por algo alheio a ela. O resultado da forma e também da função é decorrente de sobreposições e associações de sentidos, o software aparece como mediador capaz de juntar através de dados elementos que estão desconexos e traduzi-los em visualidade.

Propor habitar essa espacialidade, levando em consideração o desenvolvimento do seu processo, desde a coleta da pedra até a constituição de um lugar que se projeta em direção a uma arquitetura, é uma maneira de fazer o processo reverberar em territórios inesperados. Por isso, essa é a construção de um lugar ressonante, que amplifica as ações que o antecederam e que também pode abrigar outras ações. As definições sobre como essa espacialidade vai se comportar devem aparecer durante sua prática, quando for ocupado e quando se deslocar definitivamente pelo seu lugar de origem

Se esse projeto tangencia o campo da arquitetura é na sua intima preocupação em reivindicar a percepção de atuação dessas múltiplas espacialidades, e compreender que a especificidade do lugar de onde partiu é imprescindível para se pensar o lugar onde será instalado. Stan Allen discute no seu texto Condições de campo um lugar menos sedimentado e mais "vulnerável" para a arquitetura: "uma arquitetura que não investe na durabilidade, na estabilidade e na certeza, mas deixa espaço para a incerteza do real" (Allen, 1999, p.102).

Diante dessas questões, iniciou-se a fabricação de maquetes de estudo. Essas projeções do trabalho servem como antecipação de eventuais desvios em outra escala e ao mesmo tempo podem apontar para diferentes caminhos, como outra maneira de fazer reverberar sentido ao processo. Sua potência e autonomia enquanto objeto emerge do volume processual, da justaposição do todo, cada parte é um fragmento que remonta e conduz para uma experiência. As primeiras maquetes dos protótipos foram virtuais, essa etapa de concepção digital foi importante pois possibilitou a visualização das proporções físicas dos protótipos e seu redimensionamento. Além dessa linguagem tornar possível comunicar e veicular o trabalho em diferentes plataformas, possui especificidades que apontam para outros meios possíveis de percepção do trabalho.

Figura 5: Maquete estrutural, P1 + P2, 2015.

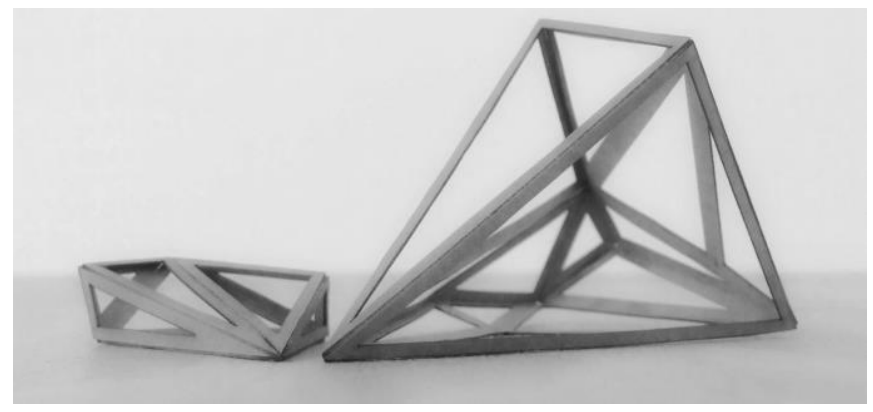

\section{Discussão}

Essa experiência que se encaminhou para o uso de ferramentas de modelagem digital tornou visível as possibilidades de representação que temos acesso. Por um lado, evidencia a necessidade de problematizar a relação mediada pelo uso da tecnologia entre o corpo e a representação do natural. Sobretudo em grandes centros urbanos podemos identificar uma aparente conformidade com a condição da experiência mediada. É habitual a relação com 0 artificial como projeção de um ambiente natural à medida que esse vai sendo banido do espaço construído, principalmente dos espaços coletivos de convívio. Nesse sentido 0 artificial se coloca como mediador de uma experiência do natural, cada vez mais individualizada, privatizada, estandardizada (Acosta, 2005). O crítico Mario Pedrosa em um artigo para o Jornal do Brasil expressou: "O homem de hoje é moderno porque não aceita o ambiente ou o meio natural passivamente" (Pedrosa, 1959, p.183).

Porém, esses mecanismos podem ser uma ferramenta de aproximação entre o indivíduo contemporâneo e os objetos instantâneos que o circunda. Na fabricação de um ambiente temporário para ocupar um determinado espaço na natureza, a ferramenta de modelagem digital viabilizou essa aproximação entre o indivíduo e um fragmento do lugar, no caso a pedra, para uma experiência estética que ultrapassa os limites visuais da forma criada a partir do software.

Além disso, percebe-se que a modelagem digital pode ser um procedimento que agrega sentido poético ao trabalho, seja ele uma obra de arte ou a fabricação de objetos utilitários. Nesse sentido, o desenho paramétrico tem assegurado cada vez mais um lugar híbrido de criação entre o design, a arte e a arquitetura.

Outra questão levantada por essa série de desdobramentos diz respeito ao que ainda permanece do modelo inicial. As características físicas e conceituais que se mantiveram ou se perderam durante esse processo trans-formato. Essa sobreposição de virtualidades é uma condição do tempo em que vivemos, onde a experiência com o real ultrapassa a fisicalidade. Nesse caso, a topologia pode ser uma maneira de traduzir sem representar, a experiência é equivalente, porém sempre será diferente. Segundo Bourriaud, o cerne principal que é a transcodificação, ou seja, a passagem de um código para outro, cria nas obras contemporâneas uma perspectiva original do espaço-tempo que corrompe as noções de origem e originalidade.

\section{Conclusão}

A pesquisa, sobre o uso de tecnologias de representação e fabricação digitais, tem sido uma ferramenta importante para os desdobramentos que seguiram após a vivência durante o período de residência. A apropriação dos meios técnicos para a produção de imagens e objetos artísticos, nesse caso, está associada a um modo de produção coletiva. Inserir-se e transitar em diferentes contextos e com isso criar associações é uma operação inerente a esse fazer.

Colocando-se na condição de estrangeiro, como sugere Bourriaud em Radicante, referindo-se a artistas que interferem diretamente na realidade em oposto a uma representação do 
real, utiliza-se de certos parâmetros para situar-se no desconhecido, para projetar raízes numa espacialidade temporária e modificá-la.

A produção de arte na zona de intersecção, nesse caso entre arte e arquitetura, tem sido uma importante ferramenta para a descoberta de novas diretrizes para esse e futuros trabalhos, criando hibridações e tensões entre processos e especificidades do meio. Em Antropoplástico houve um desvio de função dos mecanismos de leitura tridimensional e representação gráfica digital para fazer emergir no processo novas possibilidades de se enxergar os recentes equipamentos para reprodução de objetos.

Tendo em vista que essa pesquisa inicia no campo da arte para projetar uma perspectiva sobre a representação e fabricação digital, fica claro que as fronteiras entre as esferas do conhecimento estão cada vez mais diluídas. Sobretudo nas áreas da criação é corrente a interação entre os profissionais e pesquisadores para 0 desenvolvimento de projetos colaborativos híbridos.

Explorar as potencialidades de tais equipamentos modifica a forma de percepção sobre o objeto gerado. Entende-se que o encontro com essa tecnologia abriu caminhos inesperados para essa pesquisa em arte, ao passo que aponta para outros usos possíveis do equipamento no processo de criação em outras linguagens.

Figura 6: Projeto para implantação do abrigo nômade, 2015.

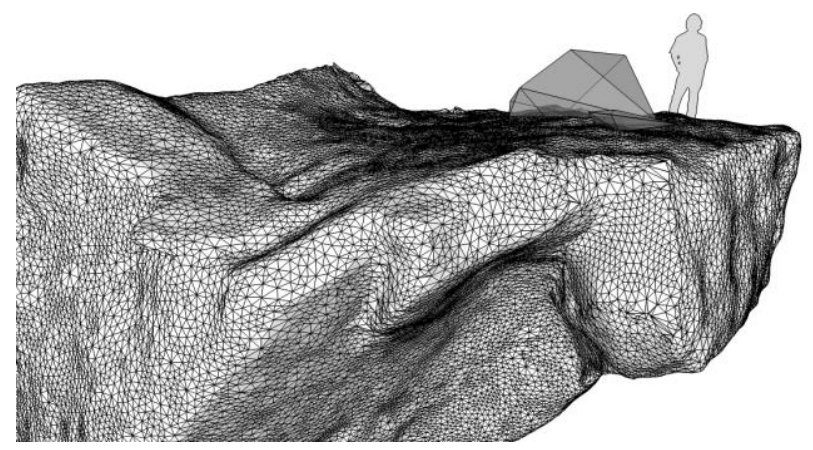

\section{Referências}

ACOSTA, Daniel Albernaz. Paisagem portátil: Arquitetura da natureza estandardizada. 2005. 86 f. Tese (Doutorado em Arte) - Escola de Comunicação e Artes, Universidade de São Paulo, São Paulo, 2005.

ALLEN, Stan. Condições de campo. In: SYKES, A. Krista [org.]. O campo ampliado da arquitetura: Antologia teórica 1993-2009 Trad: Denise Bottman. São Paulo: Cosac Naify, 2013. p. 91-103.

ARDENNE, Paul. Un arte contextual: Creación artística em médio urbano, em situación, de intervención, de participación. Cartagena: Cendeac, 2002. 176p.

BENJAMIN, Walter. O Autor como produtor: Conferência pronunciada no Instituto para o Estudo do Fascismo, em 27 de abril de 1934. In: BENJAMIN, Walter. Magia e técnica, arte e política. 1ed. São Paulo: Editora brasiliense s.a, 1985. p. 120-136.

BOURRIAUD, Nicolas. Radicante. Trad: Dorothée de Bruchard, São Paulo: Martins Fontes, 2011, 192p.

CARERI, Francesco. Walkscapes: O caminhar como prática estética. Trad: Frederico Bonaldo. 1ed. São Paulo: Editora G. Gili, 2013. 188p.

MORRIS, Robert. O tempo presente do espaço. In: FERREIRA, Glória; COTRIM, Cecilia. [orgs. ]. Escritos de artistas: anos 60/70. Trad: Pedro Süssekind. Et al. 2ed. Rio de Janeiro: Jorge Zahar Ed., 2009. p. 401-420.

PEDROSA, Mário. Arquitetura: Ensaios críticos. São Paulo: Cosac Naify, 2015. 208p. 
SIGraDi 2016, XX Congreso de la Sociedad Ibero-americana de Gráfica Digital 9-11, November, 2016 - Buenos Aires, Argentina 